\title{
What makes learning enjoyable? Perspectives of today's college students in the U.S. and Brazil
}

\author{
Corey Seemiller ${ }^{1}$, Meghan Grace², Paula Dal Bo Campagnolo ${ }^{3}$, Isa Mara Da Rosa Alves ${ }^{4}$ and \\ Gustavo Severo De Borba ${ }^{5}$ \\ ${ }^{1}$ Wright State University, Leadership Studies in Education and Organizations, USA (ORCID: 0000-0002-0707-0576) \\ 2Plaid, LLC, USA (ORCID: 0000-0002-7140-2504) \\ ${ }^{3}$ Unisinos University, Academic Manager and Graduation Unit, Brasil (ORCID: 0000-0002-8663-8077) \\ ${ }^{4}$ Unisinos University, Postgraduate Program in Applied Linguistics, Brasil (ORCID: 0000-0002-3067-700X) \\ ${ }^{5}$ Unisinos University, Undergraduate Studies Academic Unit, Brasil (ORCID: 0000-0003-2601-127X)
}

\begin{abstract}
The purpose of this article is to uncover what makes learning enjoyable for Generation $\mathrm{Z}$ college students (born 1995-2010) in the United States (U.S.) and Brazil. Qualitative data from 1,282 participants in the U.S. and 775 participants in Brazil were analyzed independently and for comparison using content analysis and thematic coding. The results of this study show both similarities and differences between these two populations. Both groups enjoy learning that is interesting, inspiring, relevant, and engaging. U.S. students enjoy knowledge acquisition, learning for societal impact, and having instructors who are competent and relatable. Brazil students, on the other hand, enjoy peer learning. While these results align with previous research findings on preferences for learning and cultural nuances, it is important to note that studies on Generation $\mathrm{Z}$ college students and learning are sparse. Thus, understanding this generational cohort in higher education is paramount for both informing and supporting individual pedagogical practices and shaping training initiatives on teaching and learning in higher education. In addition, given the impact of globalization on technology, commerce, entertainment, and information, uncovering the similarities in how young people from different cultures perceive learning may have global implications on research, training, and individual instruction in a more macro and universal way.
\end{abstract}

Keywords: Generation Z; Instruction; Learning enjoyment; International comparative learning; College students

Article History: Submitted 4 August 2020; Revised 18 November 2020; Published online 19 December 2020

\section{Introduction}

Regardless of geographic location, the primary purpose of higher education is to foster learning and development (Delbanco, 2012). But, is there a difference in how today's young people prefer to learn based on their country of residence? This article compares the perceptions of U.S. and Brazil Generation Z students born 1995-2010 (Sparks \& Honey, 2014) as to what makes learning enjoyable.

\footnotetext{
Address of Corresponding Author

Corey Seemiller, PhD, Wright State University, 3640 Colonel Glenn Hwy. Dayton, OH 45435 U.S.A.

$\triangle$ corey.seemiller@wright.edu
}

How to cite: Seemiller, C., Grace, M., Dal Bo Campagnolo, P., Mara Da Rosa Alves, I., \& Severo De Borba, G. (2020). What makes learning enjoyable? Perspectives of today's college students in the U.S. and Brazil. Journal of Pedagogical Research, 5(1), 1-17. http://dx.doi.org/10.33902/JPR.2020065267 
Contextual factors such as technological advances, political climate, social issues, and economic conditions can impact generational cohorts in different ways. The Pew Research Center (2015) further explains this phenomenon as the cohort effect, where individuals who experience similar events at similar times in their lives can end up with similar worldviews. This is particularly true if those events occur during one's adolescence and young adulthood (Pew Research Center, 2015) because those events can significantly shape the collective peer personality of the generation while coming of age (Seemiller \& Grace, 2019). But, does one's culture and geography create differing peer personalities that may affect perceptions of learning in unique ways?

\subsection{Purpose}

The purpose of this study was to better understand what makes learning enjoyable for Generation Z students in both the U.S. and Brazil. The term, "enjoy," means "to have for one's use, benefit, or lot" or "to take pleasure or satisfaction in" (Merriam-Webster, n.d.). Thus, this study aims to uncover what students in both countries find enjoyable about the process, content, or outcome of learning. In addition to uncovering the discrete findings for each country, being able to compare those findings may illuminate the aspects of learning enjoyment that reflect both universal and culturally unique peer personality characteristics.

\subsection{Literature Review}

While research on Generation Z-aged populations is sparse, global literature related to learning enjoyment, in general, can provide some insight. According to Griffin (2005), David Manson's eighteenth-century concept of "pedagogy of enjoyment," asserts that learning should be fun, playful, purposeful, and offer "enjoyable work imbued with creativity" (Griffin, 2005, 1). Thus, learning and enjoyment are closely related and intertwined (Lumby, 2011). There are a number of factors, described in the literature, that can contribute to enjoyable learning experiences, including feeling a connection to the content, having an effective instructor, participating in active learning, and engaging in learning achievement.

\subsubsection{Connection to the Content}

The connection between interest and learning dates back in the U.S. to the early 1900s with scholars such as Dewey (Schiefele, 1991). While interest is associated with other factors like meaning-making and motivation, Scheifele (1991) asserts that "feelings of enjoyment and involvement are most typical of interest" (303). Hidi and Renninger (2006) also found that interest in a topic, especially one that comes from an individual connection, can affect one's learning enjoyment.

In addition to interest, relevance also plays an important role in learning. Fredrickson (2001) affirms that cognitive processes can be enhanced when the topic is relevant or offers "a personally meaningful connection to the individual" (Priniski et al., 2018, 12). Goldman et al. (2016) found that among a list of behaviors U.S. students believe are most important for instructors to engage in, making content relevant was in the top three.

From the lens of utility, learning may be enjoyable because education can lead to a variety of future benefits. For example, as of 2017, those who completed a bachelor's degree in the U.S. earned earn on average nearly $\$ 30,000$ more per year than those who only graduated from high school (The College Board, 2019). In addition, those with a college degree also tend to be healthier, more involved with their families, and more civically involved than those who do not attend college (The College Board, 2019).

\subsubsection{Effective Instructor}

The characteristics and behaviors of the instructor are also paramount for learning enjoyment. Students want their instructors to have expertise (Goldman et al., 2016; Delaney et al., 2010; Onwuegbuzie et al., 2007), know how to effectively teach (Delaney et al., 2010), demonstrate 
professional behavior (Delaney et al., 2010; Onwuegbuzie et al., 2007), and be student-centered (Onwuegbuzie et al., 2007). Students also believe it is important that instructors are enthusiastic, good communicators, and able to make connections (Onwuegbuzie et al., 2007). Many of these characteristics hold true across discipline and modality, particularly in the U.S. In a study of nursing students, for example, participants indicated that interpersonal connections were crucial to effective instruction (Tang et al., 2005). And, in a distance learning study, participants asserted that effective instructors should be involved and connected to students and the learning environment (Young, 2006).

How much an instructor "can bring a subject to life" is also critical to teaching excellence (Revell \& Wainwright, 2009, 214). In a study of New Zealand college students by Kane et al. (2004), the most reported personality characteristic of an instructor desired by students was enthusiasm; other characteristics included passion, being approachable, and being humane. Revell and Wainwright (2009) found that UK college students believe that a lecture is unmissable when the educator is funny, excited, charismatic, motivated, passionate, and enthusiastic. A study by König (2018) found that college students in Germany who listened to an enthusiastic version of an instructor podcast compared to those who listened to a non-enthusiastic one found greater enjoyment in the learning experience as well as motivation to continue learning about the topic. And, a study of effective college teaching in Brazil points to the importance of having instructors who like what they do and who can stimulate an interest in the subject matter with students (Feldens \& Duncan, 1986).

If used appropriately and intentionally, humor can also positively influence the learning experience (Baid \& Lambert, 2010; Powell \& Anderson, 1985). In particular, one U.S. study found that students enjoy humor, especially funny stories or funny comments, from their professors (Torok et al., 2004). Researchers, Hernik and Jaworska (2018) from Poland, found that humorous delivery of content leads to greater student satisfaction and more positive feelings. And, college students in New Zealand report wanting their instructors to have a sense of humor (Kane et al., 2004).

\subsubsection{Active Learning}

Active learning, which involves students engaging in both 'doing' and 'reflecting,' has been found to be a critical factor related to effective instruction (Millis, 2012, 1). Active learning includes critical thinking and problem-solving activities, as well as experiential learning (Millis, 2012), which Kolb (1984) asserts is grounded in reflection, observation, and experimentation. Silva et al. (2018) found that engaging in problem-based learning with management students in Brazil positively contributed to students' learning motivation and meaningfulness. Revell and Wainwright (2009) found that students in the UK identified their best lectures as being those that include activities, discussions, role plays, and other interactive learning pedagogies.

In addition, gamification, which involves incorporating game structures and mechanics into learning experiences, has been found to make learning more enjoyable (Khaleel et al., 2015). An exhaustive global literature review of 18 different countries by Subhash and Cudney (2018) found that game-based learning had a positive effect on learning enjoyment. In Brazil, specifically, Silva et al. (2017) found that a large majority of students in an engineering course had a positive view of game-based learning after participating in it.

\subsubsection{Learning Achievement}

There is also a connection between cognitive development and enjoyment. Studies have shown that the ability to implement newly acquired skills is associated with increased levels of pleasure (Kashdan et al., 2004) and that when faced with different and varied tasks, feelings of enjoyment can be triggered (Watson \& Tellegen, 1985). For example, Sheldon et al. (1996) found that U.S. college students defined good days as those when they felt more competent in doing their day-today activities. 
In addition to enjoyment creating learning motivation, motivation to set and achieve goals and tasks can also create learning enjoyment. For instance, students' ability to achieve goals has been found to be associated with satisfying student experiences (Astin, 1999; Braxton et al., 2014). In particular, mastery goals, or those undertaken for the purpose of learning and not performing, have been linked to higher levels of enjoyment (Daniels et al., 2009). Further, students enjoy pursuing tasks they believe are challenging and require effort, yet are achievable (Lumby, 2011), as well as useful for accomplishing their goals - now and in the future (Eccles \& Wigfield, 2002).

\section{Method}

To better understand Generation Z college students' learning preferences in both countries, the following research question was posed: How do Generation Z college students in the U.S. and Brazil describe what makes learning enjoyable for them?

\subsection{Research Context}

Comparing students from the U.S. and Brazil presents a broader opportunity for understanding Generation $\mathrm{Z}$ than simply looking at a singular context. It's valuable then to compare both countries' overall culture and higher education landscape as well as perceptions and attitudes of those in Generation $\mathrm{Z}$ to better understand the context of this research study.

\subsubsection{Comparison of the U.S. and Brazil: Overall Culture}

In one sense, the U.S. and Brazil have great similarities. Both countries are comprised of some of the largest populations in the world, with the U.S. ranked 3rd with over 329 million citizens, and Brazil ranked 5th with over 212 million citizens (World Population Review, 2019). Economically, both countries are among the top 10 nations with the largest gross domestic product, with the U.S. ranked 3rd and Brazil ranked 9th (Central Intelligence Agency, 2017). In addition, the two countries have the largest economies in the Western Hemisphere (U.S. Department of State, 2018). Politically, in recent years, both countries experienced major presidential elections closely watched by the global population. Both candidates elected around the same time identified as right-leaning with similar viewpoints. BBC News referred to Brazil's Jair Bolsonaro as "Trump of the Tropics" (BBC, 2018). Socially, both nations are discussing, debating, and addressing issues around police brutality, freedom of speech, women's rights, immigration and asylum-seeking, sexual orientation rights, gender identity inclusion, and environmental and land-related conflicts (Human Rights Watch, 2017). Both countries have widespread access to the Internet, with 70\% or more of both populations having broadband Internet access (The World Bank, n.d.) and around 80\% owning a smartphone (Deloitte, 2017). These high rates of connectivity allow for expansive access to global news, entertainment, and communication.

Despite the similarities, both countries have their own unique histories, cultures, languages, and laws. And, regardless of their large economies, there are income disparities between both countries, in that the net-adjusted household income per capita was $\$ 45,284$ in the U.S. and $\$ 12,701$ in Brazil (OECD, 2011). In addition, there are vast differences in the societal norms and expectations within each culture. According to Hofstede's GLOBE study, which examined a variety of cultural dimensions across multiple countries, Brazil ranks higher in power distance (an accepted hierarchy of unequal power distribution), uncertainty avoidance (having structure and formal procedures in place), and long-term orientation (embracing an adaptive mindset for societal change). The U.S. ranks higher in individualism (taking care of oneself over the collective group), masculinity (having a desire for competition, achievement, and rewards), and indulgence (seeking gratification, pleasure, and fun) (Hofstede Insights, n.d.).

\subsubsection{Comparison of the U.S. and Brazil: Higher Education Landscape}

The U.S. and Brazil have several similarities in terms of their higher education systems. First, they both have high numbers of institutions, with the U.S. having 4,313 (Statista, 2017) and Brazil having 2,448 (Brazil Ministry of Education, 2018). In addition, higher education serves a large 
population of students in both countries, with the U.S. enrolling more than 18 million students (National Student Clearinghouse Research Center, 2017) and Brazil enrolling 8.3 million (Institute of National Education Studies and Research, 2017). Brazil also has a higher percentage of the general population of 18-24 year-olds who are attending college at 58.5\% (Government of Brazil, 2017) compared to $41 \%$ in the U.S. (National Center for Education Statistics, 2018c). And, with $58 \%$ in the U.S. (National Student Clearinghouse Research Center, 2018) and 57.1\% in Brazil (INEP, 2018), the majority of students in higher education are women. Face-to-face learning, versus distance learning, has also been more popular in both countries with $71 \%$ in the U.S. (National Center for Education Statistics, 2018b) and 76.8\% in Brazil taking in-person courses pre-pandemic (Brazil Ministry of Education, 2017). The percentage of students with loan debt is also similar with the U.S. at 38\% (National Postsecondary Student Aid Study, 2018) and Brazil at 37.8\% (Brazil Ministry of Education, 2017).

One of the main differences between both countries involves institutional type. The U.S. has two-year, four-year, vocational, non-profit, for-profit, public, private, and religiously-affiliated colleges and universities, offering a variety of educational options (Schloss \& Cragg, 2013), whereas, in Brazil, only 197 of the 2,448 institutions are universities but enroll 53.7\% of all students (Brazil Ministry of Education, 2017). In addition, 75\% of students in Brazil are in private institutions (Institute of National Education Studies and Research, 2017), with Catholic institutions playing an important role in the Brazilian educational system. In the U.S., only $21 \%$ of students are enrolled in private institutions (National Student Clearinghouse Research Center, 2018).

In the U.S., public institution tuition during the 2017-2018 year was $\$ 20,050$ on average; for private institutions, it was $\$ 43,139$ (National Center for Education Statistics, 2019). In Brazil, tuition at public institutions is free, whereas, for private institutions, it varies between $\$ 1,880$ and $\$ 9,690$ per year (WENR, 2019). Given the income disparity between the two countries (OECD, 2011), the cost of private tuition in Brazil is more similar to the cost of public tuition in the U.S.

\subsubsection{Comparison of the U.S. and Brazil: Generation Z Perceptions and Attitudes}

In looking specifically at perspectives of those in Generation Z, some similarities span both countries. For example, in a global study by the Varkey Foundation, similar rates emerged between those in Generation Z from the U.S. and Brazil on feeling fulfilled in one's study or work, overall happiness, anxiety about school, engagement in "good relationships," and importance of a job/career and developing skills when thinking about the future (Varkey Foundation, 2017). In addition, a study by Pearson Education on global learners found similar rates of those in Generation Z from both countries believing "education systems are not doing a good job keeping up with workforce trends" (Pearson, 2019).

In terms of differences, those from Brazil have higher rates of believing in the importance of "making a contribution to society" (Varkey Foundation, 2017), believing their "education has played an important role in shaping who [they] are as human being[s]", and believing "formal education is important" (Pearson, 2019). On the other hand, those from the U.S. had higher rates of believing that "higher education did not prepare [them] for [their] career[s]" (Pearson, 2019).

\subsection{Instrument Design}

The U.S. data was drawn from a qualitative measurement from a larger instrument, the Generation $Z$ Stories Survey. Likewise, the Brazil data was drawn from a qualitative measurement within a larger survey, the Generation Z in Brazil Survey. In the U.S. study, the question asked was, "What makes learning enjoyable for you?" In the Brazil study, the question was worded as "O que faz estudar ficar divertido para você?" which translates to "What makes learning fun for you?" The researchers in Brazil confirmed this wording provided the closest translation to the wording in the U.S. question in order to avoid construct bias and elicit similar responses from the Brazil students. 


\subsection{Participants}

For both surveys, a call for participating institutions notice was shared with higher education listservs and social media groups as well as sent to the researchers' professional networks. Once a list of interested professionals was formed, a follow-up email was sent that included email text and a survey link to forward to undergraduate students. In the Brazil study, the survey link was also posted on social media so students could access it directly. This method of participant recruitment, therefore, elicited a non-random sample.

Sample sizes were relative to each country's number of college students. For example, in 2017, more than 8 million students were enrolled in higher education in Brazil (Brazil Ministry of Education, 2017), and the sample size was 775. But, with 18 million college students in the U.S. (National Student Clearinghouse Research Center, 2018), it makes sense that the U.S. sample of 1,282 would be larger than that of Brazil. Both samples were similar in terms of gender, with $69.3 \%$ female in the U.S. and 69.5\% female in Brazil. Due to different conceptualizations of race/ethnicity in each country, racial demographic data were not comparable, and thus not reported. In addition, major/program of study information was not collected from the Brazil students, resulting in the inability to compare at a disaggregated programmatic level.

For the Brazil sample, the majority of the undergraduate students were enrolled in private universities (51 of 62 institutions were private 4-year). In the U.S., the sample was drawn primarily from public universities ( 25 of 42 institutions were public 4-year). However, it is important to note that structurally and cost-wise, public institutions in the U.S. are somewhat comparable to private institutions in Brazil (Marcus, 2015). The U.S. sample, however, also included students from 15 private universities. Table 1 outlines the details of both studies.

Table 1

Study Information

\begin{tabular}{lll}
\hline & $\begin{array}{l}\text { U.S. } \\
\text { Generation Z Stories Survey }\end{array}$ & $\begin{array}{l}\text { Brazil } \\
\text { Generation Z in Brazil Survey }\end{array}$ \\
\hline Survey dates & Dec 2016-Apr 2017 & Apr - May 2018 \\
\hline States & 21 of 50 & 3 of 26 \\
\hline Institutions & $\begin{array}{l}\text { 25 public 4-year; 10 private } \\
\text { secular 4-year, 5 private religious } \\
\text { 4-year, 2 community colleges }\end{array}$ & $\begin{array}{l}\text { 11 public 4-year; 49 private } \\
\text { secular 4-year; 2 private } \\
\text { religious 4-year }\end{array}$ \\
\hline Survey N & 2,241 & 1,481 \\
\hline Measurement N & 1,282 & 775 \\
\hline
\end{tabular}

While generalization is typically not an intended outcome of qualitative research, naturalistic generalization (Stake 1990) occurs when the population and circumstances are similar. The more similar; the more generalizable. In this study, both samples included students in the same age range (born 1995 through 2010) who were attending college during a similarly situated point in time.

Despite any naturalistic generalization that may have occurred, given the use of a non-random sample, variation between institutional types in each country, and limited comparative demographic information available, this study would not be generalizable to the entire higher education population in the U.S. or Brazil. However, the themes that emerged could help shape instructional practice as well as be more fully explored in future studies. 


\subsection{Data Analysis}

The process of qualitative data analysis for the U.S. study involved conventional content analysis where there were no pre-set categories or theories used to code content, but themes emerged naturally describing a phenomenon using participants' own words (Hsiu-Fang \& Shannon, 2005). The U.S. responses were analyzed using open coding, which calls for clustering similar concepts within the data to form categories situated in a larger classification system (Saldaña, 2013). Concepts may be associated with several categories simultaneously, and multiple categories can be grouped together to form a larger abstract heading (Corbin \& Strauss, 1990). Demuth (2013) asserts that open coding has the benefit of seeing what emerges in the data rather than what is expected to emerge. For consistency in comparison, however, the Brazil responses were analyzed using a keyword search from the themes derived from the U.S. study, along with open coding to account for any culturally specific emergent categories.

As Corbin and Strauss (1990) refer to concepts in the data as being the basic units of analysis, themes are determined based on the frequency of responses coded to a particular category. Those categories with the highest number of coded responses within each study yielded the themes discussed in this article.

While each research team used narrative analysis to better understand the views of their respective participants (Thorne, 2000), constant comparative analysis was used between the two sets of survey responses. Constant comparative analysis is the process of "taking one piece of data (one interview, one statement, one theme) and comparing it with all others that may be similar or different in order to develop conceptualisations of the possible relations between various pieces of data" (Thorne, 2000, 69). Further, comparative research involves describing the similarities and differences between separate entities (Esser \& Vliegenthart, 2017). In this study, the researchers compared themes from each country to better understand similarities and differences.

\subsection{Reliability}

Two specific forms of reliability were considered for this study: inter-rater reliability and crosscultural reliability. First, to reduce inconsistencies in coding and enhance inter-rater reliability, only one researcher from the U.S. team and two from the Brazil team coded the survey responses.

To address cross-cultural reliability, consideration of native language was paramount. Demuth (2013) discusses that good qualitative research is grounded in patterns of text that emerge in the data and that reporting on those patterns should include examples of quotes from study participants. Unlike the U.S. survey, which was in English, the Brazil survey was in Portuguese. The Brazil research team first coded the data in Portuguese allowing them to explore themes in their native language. The themes and the supporting participant quotes were then translated into English by the Brazil research team to allow for an easier comparison of patterns across the findings.

Golafshani (2003) points out the importance of rigor in qualitative research. To demonstrate rigor, there must be a means for readers to critically evaluate the research (Thorne, 2000). In this study, including participant quotes allows readers to assess the extent that the selected narratives fit with the themes within which they have been placed.

\subsection{Validity}

Three aspects of validity were considered for this study. First, while there were not multiple forms of data collected (e.g. interviews, survey responses, etc.) to triangulate, data was validated by comparing participant responses using codes and keywords, after initial open coding occurred.

Second, to assist with interpretive validity, at the time of analysis, all researchers on both the U.S. and Brazil teams worked with Generation Z-aged college students, giving them familiarity with both the content and context of the participant responses. Being able to understand the participants' perspectives is critical to accurate reporting and analysis (Johnson, 1997). 
Third, to address consensus validity, overall results from the study were discussed among all members of each research team to ensure accuracy. Any inconsistent interpretation was addressed by the team and reinterpreted more accurately.

\section{Results}

Four of the five most prominent themes that emerged from the responses about what makes learning enjoyable were the same between both sets of participants. These include being interested in the topic, learning content applicable to their career and life, having an effective instructor, and learning through interactive pedagogies. One U.S. participant sums up all of these themes by saying that learning is enjoyable "when I am passionate or interested in the subject; if the professor/instructor is charismatic and makes the learning interesting/enjoyable; if I'm able to apply the concepts to real-world projects in a hands-on way." An additional theme around content mastery emerged in the U.S. data but did not readily show up in the Brazil data. While there were many parallels conceptually at the macro-level, each culture's student population reported nuanced views of the themes on a micro-level, creating an essence of simultaneous similarity and difference.

\subsection{Interest in the Topic}

Interest in the topic was a prominent theme for both groups of participants. For the U.S. participants, their notion of interest centered on caring about the topic, reflected by comments such as, "curiosity of the subject," "subjects I care about," "want to learn about it regardless of whether or not I am required to do so," "make[s] me feel connected to the bigger world around me," and being "able to relate the curriculum to your personal life." Many discussed how new knowledge helps expose them to "different views," "opens [their] mind up to new things," as well as helps them learn "how people think and operate" and "how things can be improved or recreated entirely." One participant said, "I think learning is the most rewarding when you discover something about the world that you never knew existed; it makes you appreciate all the knowledge that is still out there for you to work towards." Another participant in the U.S. study sums up the importance of interest by saying,

I enjoy just expanding my horizons or proving my own preconceived notions wrong. I find it exhilarating to learn more about a topic that I originally knew nothing in and to make connections with information I did already know. Knowing that learning is just about building onto previous knowledge makes it almost addicting to see what else I can learn and add onto.

The Brazil participants' notion of interest also focused on the enjoyment of discovering new ideas as well as wanting to learn about content that keeps their attention, feeling challenged, and having fun. They made comments like, "Generally, I only have fun studying things I like; when something is not as interesting to me, I try to see it in a way that grabs my attention," and "It's important to be challenge[d] and like the subject. Discovering new things about something that makes sense to me is what make study[ing] fun."

\subsection{Applicable to their Career and Life}

Many participants from both countries indicated that learning is enjoyable when the content can be applied to their personal and professional lives, now and in the future. In the U.S., some participants enjoy being able to connect what they learn in the classroom with real-world examples, describing that they like learning to be more than just conceptual. For example, one participant noted that enjoyment is "the feeling I get when I used something I've learned in the real world," whereas another said, "my overall curiosity and excitement to gain something new that I can use in my life. I find learning [as] essential as eating." Many also discussed how they enjoy learning something they know they will use in the future, with comments such as "something that I'll actually use in my career" and "things that I will use later in life." One participant expressed, "It is important to me that what I am learning will not go to waste." 
The Brazil participants expressed a similar sentiment around real-world applicability, particularly in believing that their learning is enhanced when they understand the purpose of the content. One participant noted the importance of "dynamic content that is presented in a simple and direct way and that show[s] what people can do with it." In addition, several Brazil participants highlighted the importance of being able to apply what they learn to their lives. One noted that learning is enjoyable when "discussing and reflecting on what I learn, while relating the content/topic to day to day things / daily life." Others commented that what makes learning enjoyable is "knowing that I will use what I am learning in something in my life" and "the possibility of articulating knowledge with professional experience." Another said, "Studying becomes more interesting and fun to me when I think about the importance some material has in the professional context I intend to pursue."

Specifically, with U.S. participants, learning is also enjoyable when they are able to use their learning to educate or help others, with phrases such as "educate others," "help others," and "make a change in the world," describing what contributes to their learning enjoyment. One participant said, "If I can learn something that I can use to help another person, create something new, solve a problem, or expand my own self, I enjoy learning it."

In the Brazil study, but not in the U.S. study, some participants pointed out that the ability to dialogue with peers as being critical for applying knowledge. One participant said, "Videos, discussing materials with a few and good friends, learning by applying the content in a context in which I don't feel intimidated if I need to ask for help" makes learning enjoyable.

\subsection{Effective Instructor}

Having a good instructor is also important for learning enjoyment for participants in both countries. One U.S. participant sums this up for both groups by saying, "As I've quickly discovered in higher learning, it is beneficial to take professors, not classes."

First, enthusiastic and passionate instructors make learning enjoyable for both groups. Many U.S. participants described becoming energized when their instructors express excitement about teaching. One participant noted that learning is enjoyable with "professors who genuinely like teaching (MAKES A BIG DEAL)." Another said, "When they are excited to teach, I become excited to learn!" Some participants discussed the importance of passion. One shared, "If you are fortunate enough to have a professor that is truly passionate about what they do, learning will be a breeze, even for the hardest/ most boring class." Another noted,

Learning is most enjoyable when the person teaching me is passionate about the subject. Getting to see a person in their element, talking about something that gets them excited is what gets me excited to learn it.

Many Brazil participants also discussed how they enjoy having passionate and enthusiastic educators. One participant said, "We need professors with passion for what they teach [to] captivate me a lot. You can see their eyes shining because of happiness every time they speak." Others added, "Studying is great when we recognize the love, dedication and enthusiasm of the professors," and "It is really enjoyable [to] study when a teacher shows his/her happiness in be[ing] there, teaching us."

In addition, both groups enjoy learning when their instructors incorporate humor. The U.S. participants expressed sentiments such as "Learning is enjoyable when the professors are funny," have "a humorous mood," and are "witty." One Brazil participant said, "We need an inspired professor that believes what he/she does and is not teaching because he/she is obliged to do so; a professor with a good sense of humor."

Some responses solely from U.S. participants focused on wanting instructors who have strong teaching skills and experience in the field. Factors like being "intelligent," "know[ing] what and how to teach," and "having real world experience in said subject" are critical factors for them in making learning enjoyable. Specific teaching skills mentioned include "explain[ing] clearly," 
"know[ing] how to cater to various teaching needs," "teach[ing] in a way that you are able to understand," and "tak[ing] the time to make sure you know what you are learning."

Another factor that emerged primarily for the U.S. students is wanting to have respectful, relatable, and personable instructors. For example, "Being able to create a relationship with the professor makes learning enjoyable. When professors share their lives with you, it opens up an entire[ly] new point of view." One U.S. participant said, "When I can connect to the teacher, I connect to the subject easier." It isn't just professors sharing about themselves; students want their instructors to "take the time to get to know each student" as well. Although one Brazil participant discussed the importance of having "a professor that understands his/her students, and talks and interacts with them," this theme emerged to a much lesser extent in the Brazil responses than it did in the U.S. responses.

\subsection{Interactive Pedagogies}

Another theme that emerged in the U.S. and Brazil data was the desire for learning through interactive pedagogies. U.S. participants noted their preference for "visual aids," "interactive and creative assignments," "games that involve learning," "watching videos or movies, acting out or participating in simulations and labs, participating in debates and discussions," "any active discussions, art related projects, technology based type of learning," and "service activities." They equated these ideas with "less lecturing" and "physically moving around." One participant even pointed out a desire for learning outside of the classroom by saying, "I love hands-on internships, projects and field work. It's even better when I can get outside for these things, because I love being outside."

The same sentiment was shared by the Brazil participants. One noted, "When a teacher uses innovative methodologies, a subject that I believe previously that was really hard to learn becomes possible." Another identified enjoyable learning as "anything that does not involve reading slides," and another noted that learning is enjoyable when "the study habit is not traditional (open the book and read to exhaustion)." Brazil participants also discussed instructional strategies they enjoy like "mind maps or even music," "music, debates, field trips, assignments that involve creativity and interaction," and "mobility, activities, talks/discussions, interesting and visually enjoyable topics, music."

\subsection{Content Mastery}

Some U.S. participants, in particular, discussed liking the process of learning; "I love the journey of discovering. I learn much more even though if what I find is not what I wanted or hoped for." Another said, "If I weren't constantly learning, I would be standing still." For some, there was an element of challenge that made learning enjoyable. One participant said, "The best part about learning is when you suddenly are able to understand something that you've been struggling with," whereas another said, "I love when things are interesting but you have to work for them so they become rewarding as well." While this did not emerge as a prominent theme in the Brazil data, some Brazil participants noted that they "like to learn," reflecting enjoyment in the process of learning.

Many U.S. participants also expressed enjoying learning when it can help them become more informed. They shared thoughts such as "knowing every new thing I learn helps me understand the world around me a little bit better," "I feel accomplished when I learn or master a new skill," or "being able to have informed, conscious discussions with others about the topics I am learning." One participant said, "I just like the idea of acquiring knowledge. It's fun to develop as a person." And another said, "I always want to improve myself and learning is a big part of that." This factor did not emerge in the Brazil data.

There were also many references made by the U.S. students about wanting to increase their intelligence and/or be perceived as smart. Participants noted that learning is enjoyable because it contributes to the "outcome of being smarter than the average human" or "being perceived as 'knowledgeable." Another said, "For me, learning is about taking in all the things you don't know 
and blowing other people's minds." Others just want to be able to keep up in conversations. One participant said, "I love being able to learn about different things so I can have intellectual conversations with people," and another noted, "I do not like to be left out of intellectual discussions, and because of that, I aim to know as much as possible about as many different subjects as possible."

\subsection{Summary}

Table 2 highlights the primary themes from each country's respective data.

Table 2

Summary Findings

\begin{tabular}{lll}
\hline Theme & U.S. & Brazil \\
\hline Interest in the Topic & Pique curiosity, create a & Be fun, challenging, and be \\
"Learning should..." & connection to the larger & about an enjoyable subject.
\end{tabular}
world, expand perspectives, and be an enjoyable process.

Applicable to their Career and Life

"Learning should..."

Effective Instructor

"Instructors should..."

Interactive Pedagogies

"Instructors should use..."

Content Mastery

"New knowledge..."
Be relevant, apply to their current lives and future careers, and reflect content that helps others.

Be enthusiastic, passionate, humorous, competent, and relatable.

Diverse approaches to learning and interactive pedagogies.

Helps expose them to different views, foster selfdevelopment, learn about societal issues, and increase their intelligence.
Be relevant, apply to their current lives and future careers, and involve working with peers.

Be enthusiastic, passionate, and humorous.

Diverse approaches to learning and interactive pedagogies.

$\mathrm{N} / \mathrm{A}$

\section{Discussion}

The findings from each country's data point to both similarities and differences regarding learning and enjoyment. In terms of similarities, both groups want learning to be interesting, inspired, relevant, and engaging. The differences that emerged include the desire to learn for knowledge acquisition and societal impact, the role of peer learning, and the importance of instructor competence and relatability.

\subsection{Similarities}

First, both U.S. and Brazil students expressed enjoying learning about concepts they are interested in, aligning with previous research connecting learning and enjoyment (see Litman \& Jimerson, 2004; Kashdan et al., 2004; Sheldon et al., 1996). Further, a global comparative study by the Varkey Foundation (2017) found that $86 \%$ of those in Generation Z in the U.S. and $92 \%$ in Brazil indicated feeling fulfilled in their studies or work lives, which may be reflective of seeking fulfillment, and ultimately interest, in their educational lives. 
Second, both groups want instructors who are enthusiastic, passionate, and humorous, supporting existing research that asserts the importance of these behaviors in general (see Onwuegbuzie et al., 2007; Tang et al., 2005) and in a variety of national contexts (see Tang et al., 2005 for the U.S.; Kane et al., 2004 for New Zealand; Revell \& Wainwright, 2009 for the UK; König, 2018 for Germany; Feldens \& Duncan, 1986 for Brazil).

Third, it is not surprising that both U.S. and Brazil students discussed the importance of relevance as the findings in this study align with existing research on learning and relevance (see Goldman et al., 2016) as well as the importance of having a personal connection to the content (see Priniski et al., 2018; Yeager \& Bundick, 2009). In comparing both countries, a study by the Varkey Foundation (2017) found that around one-fifth of Generation Z respondents in both the U.S. and Brazil noted that "developing skills is the most important factor when thinking about a future career." But, $46 \%$ of U.S. and $43 \%$ of Brazil respondents indicated "education systems are not doing a good job keeping up with workforce trends." Both groups' desire for skill development, along with their feelings that education can do more, may help explain why students in both countries want their learning to be relevant.

Finally, both U.S. and Brazil participants indicated their preference for learning through diverse, engaging, and interactive pedagogies, which is in alignment with previous research highlighting college students' desire for engaging learning (see Revell \& Wainwright, 2009; Silva et al., 2018; Khaleel et al., 2015; Subhash \& Cudney, 2018). Further, both U.S. and Brazil populations have widespread access to technology and interactive smartphone apps (The World Bank, n.d.; Deloitte, 2017). With the ability to stream videos, interact on social media, play games, and use a variety of interactive tools and platforms, students have engagement at their fingertips 24 hours a day, likely setting the expectation that their educational environments are equally as engaging.

\subsection{Differences}

First, Generation Z students from the U.S. focused more on learning as a means to broaden perspectives, enhance intelligence, and develop themselves, than did those from Brazil. With a desire for meaning-making (Yeager \& Bundick, 2009) and to quell feelings of deprivation or discomfort of not knowing (Litman \& Jimerson, 2004), it makes sense that learning for the sake of developing competence is important. However, this finding emerged primarily with U.S. students, likely due to cultural differences between the two countries. For example, the U.S. has higher levels of individualism (focusing on oneself over the group) and masculinity (focusing on achievement and competition) (Hofstede Insights, n.d.), which may reflect, to some extent, the desire by some in the U.S. to engage in educational pursuits as an individual, achievementoriented activity.

Second, the U.S. students expressed an interest in wanting to learn about societal issues and use that learning to "make a change in the world." This finding aligns with Yeager and Bundick (2009) who assert that having a purpose that reflects personal meaning and community contribution is associated with learning. However, this finding did not emerge in the Brazil data. Perhaps the U.S.'s lower level of power distance, meaning there is less acceptance of unequal power distribution in society, (Hofstede Insights, n.d.) compared to that of Brazil serves as a motivator for U.S. students to strive to address inequality and disrupt current systems and structures because they believe those are more malleable. In addition, Brazil's higher level of uncertainty avoidance, in which formalized processes and structures are in place (Hofstede Insights, n.d.), may shape the type of impact Brazil students may feel they can make in society.

Third, the Brazil students, but not those in the U.S., expressed a desire for peer learning. This distinction may be more culturally embedded, however, in that Brazil has higher rates of collectivism than the U.S. (Hofstede Insights, n.d.), meaning that culturally, there is more of a focus on working together to benefit the whole. This is vastly different than the higher levels of individualism in the U.S., where the focus is more on oneself (Hofstede Insights, n.d.). 
Fourth, research has shown that students want instructors who have expertise in the content they are teaching and know how to effectively teach (see Delaney et al., 2010; Goldman et al., 2016, Onwuegbuzie et al., 2007). This specific finding emerged in the U.S. data but not in the Brazil data in this study. However, previous research has found that students in Brazil want their instructors to "demonstrate assured understanding" and "have a profound knowledge of the content" (Feldens \& Duncan, 1986, p. 645). More research may be required to uncover the reasoning for the absence of this theme among the Brazil students in this study, given previous research findings.

Finally, it was clear from the findings that U.S. students want instructors who are personable, relatable, and take the time to create relationships with them. Previous research has demonstrated the value of instructors being able to connect with their students (see Onwuegbuzie et al., 2007). However, this finding did not present itself as readily among the Brazil students' responses. This may be explained by cultural differences in that in the U.S., which has lower uncertainty avoidance, meaning there are fewer structures and formalized processes in place (Hofstede Insights, n.d.), than Brazil, it may be more acceptable to create a relationship with an authority figure, such as an instructor.

\section{Limitations}

The most significant limitation centers on the language differences between the two populations studied. The U.S. surveys were administered and analyzed in the country's primary language, English. The Brazil surveys, however, were translated from English to Portuguese, administered and analyzed in Portuguese, and then findings were translated back to English, offering the opportunity for mistranslation or misinterpretation to occur.

In addition, survey responses were coded by each country's research team. Although the coding sheet from the U.S. study was provided to the researchers in Brazil to attempt to increase interrater reliability, there may be some inconsistencies with qualitative interpretation when different people analyze and code data.

Finally, for both studies, the sample sizes were small and included student samples representing different institutional types, which may account for a variance in learning preferences. Also, the data in this study was not disaggregated by demographic group like race or those in a particular program of study, making the findings broad and not generalizable across higher education as a whole.

\section{Implications and Recommendations}

There are practical and research implications for this study that can have both a micro and macro effect on student learning in higher education.

(1) Through the findings of this study, educators in both the U.S. and Brazil are able to understand more about what makes learning enjoyable for a new demographic of college students in their respective countries. This can help them adapt their learning environments and experiences to align better with this generation in each cultural context.

(2) Identifying similarities in learning preferences that span two cultural contexts can highlight elements of learning that may be more universal for this generation.

(3) While this study offered a comparative analysis of only two countries, it can serve as a foundation for expanding research across a multitude of additional nations to gain a more holistic perspective of the global nature of student learning and discern similarities and differences in learning enjoyment.

\section{Conclusion}

While in some respects, there appear to be nuanced differences between Generation $\mathrm{Z}$ students from the U.S. and those from Brazil, there also seem to be similarities. Both groups are seeking passionate, enthusiastic, and engaging instructors who can use interactive pedagogies to help them 
learn about subject matter they are interested in and that is useful to their lives now and in the future. With knowledge about this generation's learning preferences, instructors in both countries can be better equipped to educate this population of students, while cross-cultural educators can integrate teaching methods that may have more universal appeal.

\section{References}

Astin, A. W. (1999). Student involvement: A developmental theory for higher education. Journal of College Student Development, 40(5), 518-529.

Baid, H., \& Lambert, N. (2010). Enjoyable learning: The role of humour, games, and fun activities in nursing and midwifery education. Nursing Education Today, 30(6), 548-552. https://doi.org/10.1016/j.nedt.2009.11.007

BBC. (2018). Jair Bolsonaro: Brazil's firebrand leader dubbed the Trump of the tropics. https://www.bbc.com/news/world-latin-america-45746013

Braxton, J.M., Doyle, W.R., Hartley III, H.V., Hirschy, A.S., Jones, W.A., \& McLendon, M.K. (2014). Rethinking college student retention. Jossey-Bass.

Brazil Ministry of Education. (2017). National Institute of Educacional Studies and Research Anísio Teixeira (NIESR). Higher education census: Statistic notes. Education Ministry.

Central Intelligence Agency. (2017). The world factbook: Country comparison: GDP (Purchasing power parity). https://www.cia.gov/library/publications/the-world-factbook/rankorder/2001rank.html

Corbin, J., \& Strauss, A. (1990). Grounded theory research: Procedures, canons, and evaluative criteria. Qualitative Sociology, 13(1), 3-21. https://doi.org/10.1007/BF00988593

Daniels, L. M., Stupnisky, R. H., Pekrun, R., Haynes, T. L., Perry, R. P., \& Newall, N. E. (2009). A longitudinal analysis of achievement goals: From affective antecedents to emotional effects and achievement outcomes. Journal of Educational Psychology, 101, 948-963. http://doi.org/10.1037/a0016096

Delaney, J. G., Johnson, A. N., Johnson, T. D., \& Treslan, D. L. (2010). Students' perceptions of effective teaching in higher education. Distance Education and Learning Technologies.

Delbanco, A. (2012). College: What it was, is, and should be. Princeton University Press.

Deloitte. (2017). Global mobile consumer trends, $2^{\text {nd }}$ edition. https://www2.deloitte.com/content/dam/ Deloitte/us/Documents/technology-media-telecommunications/us-global-mobile-consumer-surveysecond-edition.pdf

Demuth, C. (2013). Ensuring rigor in qualitative research within the field of cross-cultural psychology. In Y. Kashima, E. S. Kashima, and R. Beatson (Eds.), Steering the Cultural Dynamics (pp. 34-40). International Association for Cross-Cultural Psychology.

Eccles, J. S., \& Wigfield, A. (2002). Motivational beliefs, values, and goals. Annual Review of Psychology, 53, 109-132. https://doi.org/10.1146/annurev.psych.53.100901.135153

Esser, F. \& Vliegenthart, R. (2017). Comparative research methods. In J. Matthes, C. S. Davis, and R. F. Potter (Eds.), The International Encyclopedia of Communication Research Methods (pp. 1-22). John Wiley \& Sons, Inc.

Feldens, M. D. G. F., \& Duncan, J. (1986). Improving university teaching: What Brazilian students say about their teachers. Higher Education, 15(6), 641-649.

Fredrickson, B. L. (2001). The role of positive emotions in positive psychology: The broaden-and-build theory of positive emotions. American Psychologist, 56, 218-226. https://doi.org/10.1037/0003066X.56.3.218

Golafshani, N. (2003). Understanding reliability and validity in qualitative research. The Qualitative Report, 8(4), 597-606. https://nsuworks.nova.edu/tqr/vol8/iss4/6

Goldman, Z. W., Cranmer, G. A., Sollitto, M., Labelle, S., \& Lancaster, A. L. (2016). What do college students want? A prioritization of instructional behaviors and characteristics. Communication Education, 66(3), 280298. http://dx.doi.org/10.1080/03634523.2016.1265135

Government of Brazil. (2017). By 2014, 58.5\% of 18- and 24-year-olds were in college. http://www.brasil.gov.br/noticias/educacao-e-ciencia/2015/12/numero-de-estudantes-universitarioscresce-25-em-10-anos

Griffin, S. (2005). Teaching for enjoyment: David Manson and his 'play school' of Belfast. Irish Educational Studies, 24(2), 133-143. https:/ / doi.org/10.1080/03323310500435398?journalCode=ries20

Hernik, J., \& Jaworska, E. (2018, March 5-7). The effect of enjoyment on learning [Conference proceedings]. International Technology, Education and Development Conference, Valencia, Spain. https://doi.org/10.21125/inted.2018.1087 
Hidi, S., \& Renninger, K. A. (2006). The four-phase model of interest development. Educational Psychologist, 41, 111-127. https://doi.org/10.1207/s15326985ep4102_4

Hofstede Insights. (n.d.). Compare countries. https://www.hofstede-insights.com/

Hsiu-Fang, H., \& Shannon, S. E. (2005). Three approaches to qualitative content analysis. Qualitative Health Research, 15(9), 1277-1288. https://doi.org/10.1177/1049732305276687

Human Rights Watch. (2017). Brazil: Events of 2017. https://www.hrw.org/world-report/2018/countrychapters/brazil

INEP. (2018). Mulheres são maioria na Educação Superior brasileira. http://portal.inep.gov.br/artigo//asset_publisher/B4AQV9zFY7Bv/content/mulheres-sao-maioria-na-educacao-superiorbrasileira/21206

Institute of National Education Studies and Research. (2017). Statistical synopsis higher education statisticsundergraduate. http:// portal.inep.gov.br/web/guest/sinopses-estatisticas-da-educacao-superior

Johnson, R. B. (1997). Examining the validity structure of qualitative research. Education, 118(2), 282-292.

Kane, R., Sandretto, S., \& Heath, C. (2004). An investigation into excellent tertiary teaching: Emphasising reflecting practice. Higher Education, 47, 283-310. https://doi.org/10.1023/B:HIGH.0000016442.55338.24

Kashdan, T. B., Rose, P., \& Fincham, F. D. (2004). Curiosity and exploration: Facilitating positive subjective experiences and personal growth opportunities. Journal of Personality Assessment, 82(3), 291-305. https://doi.org/10.1207/s15327752jpa8203_05

Khaleel, F. L., Ashaari, N. S., Wook, T. S. M. T., \& Ismail, A. (2015. April 21-23). User-enjoyable learning environment based on gamification elements [Paper presentation]. International Conference on Computer, Communication, and Control Technology, Kuching, Sarawak, Malaysia. https://doi.org/10.1109/I4CT.2015.7219570

Kolb, D. A. (1984). Experiential learning: Experience as the source of learning and development. Prentice Hall.

König, L. (2018). Podcasts in higher education: teacher enthusiasm increases students' excitement, interest, enjoyment, and learning motivation. Educational Studies, 87, 192-206. https://doi.org/10.1080/03055698.2019.1706040

Litman, J. A., \& Jimerson, T. L. (2004). The measurement of curiosity as a feeling of deprivation. Journal of Personality Assessment, 82(2), 147-157. https://doi.org/10.1207/s15327752jpa8202_3

Lumby J. (2011). Enjoyment and learning: Policy and secondary school learners' experience in England. British Educational Research Journal, 37(2), 247-264. https:// doi.org/10.1080/01411920903540680

Marcus, J. (2015). Brazil: Where free universities largely serve the wealthy. https://www.theatlantic.com/education/archive/2015/04/brazil-where-free-universities-largely-servethe-wealthy/389997/

Merriam-Webster. (n.d.). Enjoy. https://www.merriam-webster.com/dictionary/enjoy

Millis, B. J. (2012). Active learning strategies in face-to-face classes. IDEA paper \#53." The IDEA Center. https://www.ideaedu.org/Portals/0/Uploads/Documents/IDEA\%20Papers/IDEA\%20Papers/PaperI DEA_53.pdf

National Center for Education Statistics. (2018a). 2015-2016 National Postsecondary Student Aid Study (NPSAS: 16): Student financial aid estimates for 2015-16. https:/ / nces.ed.gov/ pubs2018/2018466.pdf

National Center for Education Statistics. (2018b). The condition of education: Characteristics of postsecondary faculty. https://nces.ed.gov/programs/coe/indicator_csc.asp

National Center for Education Statistics. (2018c). The condition of education: Undergraduate enrollment. https://nces.ed.gov/programs/coe/indicator_cha.asp

National Center for Education Statistics. (2019). Digest of education Statistics, 2018 (NCES 2020-009), Table 330.10. https://nces.ed.gov/fastfacts/display.asp?id=76

National Postsecondary Student Aid Study. (2018). 2015-2016 national postsecondary student aid study (NPSAS: 16): Student financial aid estimates for 2015-16. https:/ / nces.ed.gov/ pubs2018/2018466.pdf

National Student Clearinghouse Research Center. (2018). Term enrollment estimates: Fall 2018. https://nscresearchcenter.org/wp-content/uploads/CurrentTermEnrollmentReport-Fall-2018-3.pdf

OECD. (2011). OECD better life index. http://www.oecdbetterlifeindex.org/topics/income/

Onwuegbuzie, A. J., Witcher, A. E., Collins, K. M. T., Filer, J. D., Wiedmaier, C. D., \& Moore, C. W. (2007). Students' perceptions of characteristics of effective college teachers: A validity study of a teaching evaluation form using a mixed-methods analysis. American Educational Research Journal, 44(1), 113-160. https://doi.org/10.3102/0002831206298169

Pearson. (2019). The global learner survey. https://www.pearson.com/content/dam/globalstore/global/resources/Pearson_Global_Learner_Survey_2019.pdf 
Pew Research Center. (2015). The whys and hows of generations research. https:/ / www.pewresearch.org/politics/2015/09/03/the-whys-and-hows-of-generations-research/

Powell, J. P., \& Andresen, L. W. (1985). Humour and teaching in higher education. Studies in Higher Education, 10(1), 79-90. https:// doi.org/10.1080/03075078512331378726

Priniski, S. J., Hecht, C. A., \& Harackiewicz, J. M. (2018). Making learning personally meaningful: A new framework for relevance research. The Journal of Experimental Education, 86(1), 11-29. https://doi.org/10.1080/00220973.2017.1380589

Revell, A., \& Wainwright, E. (2009). What makes lectures 'unmissable'? Insights into teaching excellence and active learning. Journal of Geography in Higher Education, 33(2), 209-223. https:/ / doi.org/10.1080/03098260802276771

Saldaña, J. (2013). The coding manual for qualitative researchers (2nd ed.). SAGE.

Schiefele, U. (1991). Interest, learning, and motivation. Educational Psychologist, $26(3$ \& 4), 299-323. https://doi.org/10.1080/00461520.1991.9653136

Schloss, P. J., \& Cragg, K. M. (2013). Organization and administration in higher education. Routledge.

Authors. (2019). Generation Z: A century in the making. Routledge.

Sheldon, K. M., Ryan, R., \& Reis, H. T. (1996). What makes for a good day? Competence and autonomy in the day and in the person. Personality and Social Psychology Bulletin, 22(12), 1270-1279. https://doi.org/10.1177/01461672962212007

Silva, E. D., Macedo, M., Teixeira, C., Lanzer, E., \& Graziani, Á.P. (2017). Game-based learning: Analysis of students' motivation, performance, and drop out in a production engineering course. In J. Kantola, $\mathrm{T}$. Barath, S. Nazir, \& T. Andre (Eds.), Advances in Human Factors, Business Management, Training and Education. Advances in Intelligent Systems and Computing, 498, 933-945. https://doi.org/10.1007/978-3-31942070-7_86

Silva, A.B.D., Bispo, A.C.K.d.A., Rodriguez, D.G., \& Vasquez, F.I.F. (2018). Problem-based learning: A proposal for structuring PBL and its implications for learning among students in an undergraduate management degree program. Revista de Gestão, 25(2), 160-177. https://doi.org/10.1108/REGE-03-2018030

Sparks \& Honey. (2014). Meet Gen Z: Forget everything you learned about Millennials. www.slideshare.net/sparksandhoney/generation-z-final-june-17

Stake, R. E. (1990). Situational context as influence on evaluation design and use. Studies in Educational Evaluation, 16, 231-246. https://doi.org/10.1016/S0191-49X(05)80027-6

Statista. (2017). Number of higher education institutions in the United States from 1980-2017. https://www.statista.com/statistics/240833/higher-education-institutions-in-the-us-by-type/

Subhash, S., \& Cudney, E. A. (2018). Gamified learning in higher education: A systematic review of the literature. Computers in Human Behavior, 87, 192-206. https://doi.org/10.1016/j.chb.2018.05.028

Tang, F., Chou, S., \& Chiang, H. (2005). Students' perceptions of effective and ineffective clinical instructors. Journal of Nursing Education, 44(4), 187-192. https:/ / doi.org/10.3928/01484834-20050401-09

The College Board. (2019). Education pays: The benefits of higher education for individuals and society. https:/ / research.collegeboard.org/pdf/education-pays-2019-full-report.pdf

The World Bank. (n.d.). Individuals using the Internet (\% of population). https://data.worldbank.org/indicator/IT.NET.USER.ZS

Thorne, S. (2000). Data analysis in qualitative research. Evidence-Based Nursing, 3, 68-70. https://doi.org/10.1136/ebn.3.3.68

Torok, S. E., McMorris, R. F., \& Lin, W. (2004). Is humor an appreciated teaching tool? College Teaching, 52(1), 14-20. https://doi.org/10.3200?CTCH.52.1.14-20

Varkey Foundation. (2017). Generation Z: Global citizenship survey. https://www.varkeyfoundation.org/media/4487/global-young-people-report-single-pages-new.pdf

Watson, D. \& Tellegen, A. (1985). Toward a consensual structure of mood. Psychological Bulletin, 98, 219-235. https:// doi.org/10.1037/0033-2909.98.2.219

WENR. (2019). Education in Brazil. https://wenr.wes.org/2019/11/education-in-brazil

World Population Review. (2019). Total population by country 2019. http://worldpopulationreview.com/countries/

Yeager, D. S., \& Bundick, M. J. (2009). The role of purposeful work goals in promoting meaning in life and in schoolwork during adolescence. Journal of Adolescent Research, 24, 423-452. https://doi.org/10.1177/0743558409336749 
Young, S. (2006). Student views of effective online teaching in higher education. Journal of Distance Education, 20(2), 65-77. https://doi.org/10.1207/s15389286ajde2002_2 